\title{
10 health stories that mattered: Nov. 4-8
}

- Canadian Forces' families are four times less likely to have a family physician than civilian families due to frequent relocations, according to a report by the ombudsman for the Department of National Defence and the Canadian Forces. Military families report concerns about extended periods without access to health care and the effects of deployments on the health, behaviour and academic performance of their children.

- An investment of $\$ 7.5$ million to fund 19 research projects on concussion will be made by the Canadian Institutes of Health Research and several other research groups. Five of the research projects will focus on mild traumatic brain injury in children and youth.

- The federal government can improve health care in Canada by establishing and upholding national standards, providing adequate funding to health care providers and creating national programs to meet health needs, states The College of Family Physicians of Canada. In its Report Card 2013, the college graded the federal government's performance in many areas, including support for electronic medical records ("somewhat involved") and a national immunization strategy ("no involvement"). The only area to receive a grade of "strong leadership" was the government's national homelessness plan.

- More Ontario health care workers should get the flu shot, according to Dr. Arlene King, the province's chief medical officer. The government is strongly encouraging health care workers to be immunized every year but hasn't made it mandatory. Currently, about half of hospital workers and three-quarters of employees in long-term care homes get inoculated, King told the Toronto Star.

- A voluntary withdrawal of 108 lots of nutrition shakes and protein drinks containing the antibiotic chloramphenicol has been issued by a British Columbia natural health products company. The company, Vancouverbased Vega, had initially refused Health Canada's recall request "despite the potentially serious risks posed to health."

- Spouses of Ontario health care professionals may soon be exempt from a zero-tolerance ban on sex with patients, reports the National Post. The ban had put doctors, dentists and other health care professionals at risk of sexual abuse charges for treating their spouses, which had proved inconvenient for providers in remote areas. The Ontario legislature had passed a private member's bill that would leave the exemption decision to professional regulatory colleges, the National Post reports.

- Midwifery deserves more government support to improve maternal and newborn health outcomes, particularly in resource-starved remote locations, according to the Canadian Association of Midwives. "Our government made a commitment to global maternal newborn health, but we need that same commitment to women and newborns in Canada," association president Joanna Nemrava told the Ottawa Citizen.

- About $66 \%$ of Alberta health workers follow a proper hand hygiene protocol and that is "nowhere near high enough," announced the province's health minister, Fred Horne. Concerns have been raised about controlling infections during flu season due to improper handwashing.

- Quebec seniors must leave hospitals within eight days of being declared medically stable or health agencies will face $\$ 984$ fines for each day an elderly patient occupies a bed, reports the Montreal Gazette. The Quebec Health Department has announced about $\$ 16$ million in new funding for a program intended to free beds for patients requiring acute care.

- Replacing the public service sick leave policy with a short-term disability plan to reduce absenteeism will be a top government priority in 2014, Treasury Board President Tony Clement reiterated this week. According to Clement, the average public servant takes 18.2 days in paid and unpaid sick leave a year, two-and-ahalf times of that in the private sector. Public sector unions, however, plan to fight proposed changes to the sick leave policy and claim Clement is inflating absenteeism statistics. Roger Collier, CMAJ

CMAJ 2013. DOI:10.1503/cmaj.109-4657 